\title{
Molecular Organization of the Olfactory Septal Organ
}

\author{
Huikai Tian and Minghong Ma \\ Department of Neuroscience, University of Pennsylvania, Philadelphia, Pennsylvania 19104
}

The septal organ in the mammalian nose is a distinct chemosensory organ sitting in the air path. To gain insights into its organization and function, we analyzed the chemoreceptors expressed in this area. By combining cDNA cloning, Affymetrix (Santa Clara, CA) genechips covering all the mouse olfactory receptor genes, and in situ hybridization, we achieved a relatively complete expression profile of the olfactory receptor genes in the septal organ. The majority of the septal neurons express only a few receptor genes in varying patterns, with the top one in $\sim 50 \%$ of the cells and the top eight together in $\sim 93 \%$ of the cells. We demonstrated that a single neuron expresses only one receptor by a thorough combination of all the major septal receptor genes in double-labeling studies. These septal receptor genes do not form a single subfamily. Instead, these genes are distributed on a few major branches of the phylogenetic tree covering all the mouse olfactory receptors. Most of these genes are also concentrated in certain areas within the most ventral zone of the main olfactory epithelium, although their expression patterns do not match those in the septal organ. In contrary to the previous view of random distribution, our results indicate that certain olfactory receptors form "hot spots" in the nose.

Key words: septal organ; olfactory receptor; main olfactory epithelium; olfactory sensory neuron; microarray; genechip

\section{Introduction}

The mammalian nose contains several distinct chemosensory organs, including the main olfactory epithelium (MOE), the vomeronasal organ (VNO), and the septal organ. The function of each organ depends primarily on what receptors they express, what chemicals they detect, and where in the brain they send the information. In the past decade, identification of the receptor genes in the MOE and VNO became a critical step leading to a great expansion of our knowledge on molecular wiring and functions of these two systems. The rodent MOE expresses > 1000 G-proteincoupled olfactory receptors forming a superfamily (Buck and Axel, 1991; Young et al., 2002; Zhang and Firestein, 2002), and the VNO expresses two types of putative pheromone receptors in the two distinct VNO compartments (Dulac and Torello, 2003).

In contrast, little is known about the chemoreceptors expressed in the septal organ, whose function consequently remains elusive. The septal organ is a small patch of olfactory neuroepithelium at the ventral base of the nasal septum found in many mammals (Rodolfo-Masera, 1943; Adams and McFarland, 1971; Kratzing, 1984). Because most of the sensory neurons in this area express olfactory-specific G-protein $\left(\mathrm{G}_{\text {olf }}\right)$ (Ma et al., 2003), we hypothesized that the septal organ, similar to the MOE, expresses G-protein-coupled olfactory receptors from the same superfamily (Kaluza et al., 2004). A major goal of this study was to identify

Received June 8, 2004; revised Aug. 11, 2004; accepted Aug. 13, 2004.

This work was supported by grants from the National Institutes of Health-National Institute on Deafness and Other Communication Disorders (DC005127 and DC006213) and the Whitehall Foundation. We are indebted to Drs. Gordon Shepherd, Charles Greer, Wei Chen, Philip Haydon, and Peter Sterling for their encouragement and insightful discussion. We thank Drs. Carrie Iwema, Tomo Ishii, and Stefan Fuss for helping us with in situ hybridization, Dr. Xinmin Zhang for analyzing the receptor genes, and Jian Liu for technical assistance. We thank Dr. Mike Nusbaum for his critical inputs on this manuscript and Dr. Steve Moss for his generous permission to use the confocal microscope.

Correspondence should be addressed to Dr. Minghong Ma, Department of Neuroscience, University of Pennsylvania, 215 Stemmler Hall, 3450 Hamilton Walk, Philadelphia, PA 19104. E-mail: minghong@mail.med.upenn.edu. DOI:10.1523/JNEUROSCI.2222-04.2004

Copyright $\odot 2004$ Society for Neuroscience $\quad$ 0270-6474/04/248383-08\$15.00/0 a relatively complete list of receptor genes (from a pool of $\sim 1400$ ) in the septal organ. By combining cDNA cloning and Affymetrix (Santa Clara, CA) genechips covering all the mouse olfactory receptors (MOR) genechips (Zhang et al., 2004), we identified 84 candidate genes. Using in situ hybridization, we demonstrated that the expression patterns of these genes in the septal organ vary tremendously. The most abundant receptor gene (MOR256-3) is expressed in $\sim 50 \%$ of the cells and the top eight together in $\sim 93 \%$ of the cells, indicating that we obtained a nearly complete profile.

We further tested the hypothesis that a single cell expresses only one receptor gene by a thorough examination of the major genes using double in situ hybridization. Such evidence has been lacking for the MOE because of the vast number of receptor genes expressed in any given area (Mombaerts, 2004). The major septal receptor genes fall into a few subfamilies and are also expressed in the MOE, but with expression patterns that do not mirror those in the septal organ. In addition, these receptors appeared concentrated in some areas of the MOE. Furthermore, the rat septal organ expresses the same set of olfactory receptors at comparable levels as the mouse. These results indicate that a defined subset of olfactory receptors is placed in the septal organ with unusually high densities, which lays a molecular foundation for a common function of this enigmatic organ across different species.

\section{Materials and Methods}

Molecular cloning. Two male and two female groups of C57BL/6 mice (8-16 weeks, five animals in each group) were deeply anesthetized and decapitated. The septal organ was harvested under a microscope, where it was readily separated from the MOE to avoid any contamination from the latter (Ma et al., 2003), and immersed in RNAlater solution immediately. Total RNAs were isolated using the RNeasy Mini kit with an oncolumn DNase digestion step to eliminate genomic DNA contamination. One-step reverse transcriptase (RT)-PCR was used to synthesize cDNA and amplify olfactory receptor gene products using the following degen- 
erate primers: 5' (ATG GCI T(T/A)(T/C) GA(T/C) (C/A)GI T(T/A)(T/C) (T/C/G)TI GC) and $3^{\prime}$ (AT IA(A/T/G) IGG (G/A)TT IA(A/G)CAT. The PCR products were subject to TA cloning into pCRII vectors (Invitrogen, Carlsbad, CA), and selected clones were sequenced. For each group, we stopped sequencing when fewer than two new sequences were obtained from 20 colonies. The partial sequences were matched to their full-length sequences in GenBank by BLAST. The chromosome location of the receptor genes was determined using BLAT search from the public database of the assembled C57BL mouse genome. All reagents in this section were from Qiagen (Valencia, CA) if not otherwise stated.

Affymetrix MOR genechip. A high-density oligonucleotide array was produced using the Affymetrix genechip technology to cover all the mouse olfactory receptor genes $(\sim 1400)$ (Zhang et al., 2004). Extra care was taken during the design of these genechips to achieve the highest specificity and selectivity. This was mainly done by adding probe sets based on the 3' UTR sequences, which helped to distinguish very similar genes and make the probes closer to the poly(A) site. Most of the receptor genes $(95.9 \%)$ have at least one unique probe set, which contains 11 matched and 11 mismatched oligomers (all the probe sequences are available as supplementary data in the report by Zhang et al., 2004). Four total RNA samples, two from the septal organ (each pooled from 15-20 animals) and two from the MOE (each pooled from five animals), were extracted and sent to Yale Affymetrix core facility for cDNA and biotin-labeled cRNA synthesis and hybridization onto the MOR genechips following the standard Affymetrix protocol. The data were analyzed using Affymetrix Microarray Suite 5.0, and different samples were scaled and normalized using all probe sets. The fold changes (septal organ vs MOE) were calculated using the $\mathrm{MOE}$ as the comparison baseline, and the statistic $p$ value was set as $<0.05$ for any significant change.

In situ hybridization. Eleven mice (both male and female, $\sim 8-12$ weeks old) and two male Sprague Dawley rats (4 weeks old) were used. The nose was cut into $20 \mu \mathrm{m}$ sections on a cryostat following standard procedure. The septal organ was $\sim 600-\mu \mathrm{m}$-long (anterior to posterior) with fewer cells at each end. The sections from the middle $400 \mu \mathrm{m}$ were used in this study to reduce variations caused by the actual positions. Digoxigenin (DIG)-labeled RNA probes of the olfactory receptor genes covering $\sim 400-500$ bp of the coding regions were generated using DIG RNA labeling kit (SP6/T7). The sections were hybridized with the RNA probes $(\sim 1 \mu \mathrm{g} / \mathrm{ml})$ overnight at $65^{\circ} \mathrm{C}$ in the hybridization solution $(50 \%$ deionized formamide, $10 \mathrm{~mm}$ Tris-Cl, $\mathrm{pH} 8.0,10 \%$ dextran sulfate, $1 \times$ Denhardt's solution, $200 \mu \mathrm{g} / \mathrm{ml}$ tRNA, $0.6 \mathrm{M} \mathrm{NaCl}, 0.25 \%$ SDS, and $1 \mathrm{~mm}$ EDTA), followed by high-stringency washing steps sequentially in $2 \times$, $0.2 \times$, and $0.1 \times$ SSC at $65^{\circ} \mathrm{C}$. The sections were then incubated with alkaline phosphatase (AP)-conjugated anti-DIG antibody, and the signals were detected by nitroblue tetrazolium and 5-bromo-4-chloro-3indolyl phosphate. Such high-stringency washes assured specificity of the RNA probes (see Results).

In double in situ hybridization experiments, the tissue sections were hybridized with fluorescein (FLU)-labeled and DIG-labeled probes together. After high-stringency washing steps, the sections were reacted with horseradish peroxidase (HRP)-anti-FLU (1:100) and AP-anti-DIG (1:1000) antibodies followed by incubation in Tyramide-biotin (1:50)
(PerkinElmer, Boston, MA) to amplify the peroxidase signal. The signals were visualized by Streptavidine-Alexa 488 (Molecular Probes, Eugene, OR) and Fast Red (2-Hydroxy-3-naphthoic acid-2'-phenyl-anilide phosphate fluorescent detection set), respectively. The pictures were taken under a confocal microscope (Nikon Eclipse E600). All reagents in this section were from Roche (Indianapolis, IN) if not otherwise stated.

\section{Results}

\section{The septal organ expresses a defined subset of olfactory} receptor genes at different levels

The septal organ is located at the ventral base of the nasal septum, sitting in the air path (Fig. $1 A$ ). Because its size is $\sim 1 \%$ of the MOE, and most neurons in this area express $G_{\text {olf }}$ (Ma et al., 2003), we hypothesized that the septal organ expresses a subset of the G-protein-coupled olfactory receptor genes from the same superfamily as the MOE. We first took a standard cDNA cloning approach to identify candidate receptor genes using degenerate primers based on the conserved regions of the mouse olfactory receptors (Zhang and Firestein, 2002). Four RNA samples (two male and two female) from independently pooled septal organs were used to obtain as many candidates as possible. Because we did not observe any significant gender differences, we treated 
Table 1. Summary of the olfactory receptor genes expressed in the septal organ confirmed by different means

\begin{tabular}{|c|c|c|c|c|c|c|}
\hline & Gene name & $\begin{array}{l}\text { NBT-BCIP-positive cells per } \\
\text { section (mean } \pm S D \text { ) }\end{array}$ & $\begin{array}{l}\text { Percentage in 0MP-positive } \\
\text { cells (mean } \pm \text { SD) }\end{array}$ & $\begin{array}{l}\text { Fold-change ( } \mathrm{SO} \text { vs } \\
\mathrm{MOE} \text { ) in genechips }\end{array}$ & $\begin{array}{l}\text { cDNA } \\
\text { cloning }\end{array}$ & $\begin{array}{l}\text { Specific } \\
\text { RT-PCR }\end{array}$ \\
\hline Category I & MOR256-3 & & $49.8 \pm 0.9 \% ; n=12$ & 31.1 & & + \\
\hline \multirow[t]{7}{*}{ Category II } & MOR244-3 & $35.7 \pm 12.1 ; n=18$ & $12.2 \pm 0.8 ; n=10$ & 26.3 & & + \\
\hline & $\mathrm{MORO}-2^{a}$ & $23.9 \pm 8.8 ; n=16$ & 8.0 & 7.2 & & + \\
\hline & MOR235-1 & $19.4 \pm 8.6 ; n=17$ & 6.5 & 3.2 & ++++ & \\
\hline & MOR160-2 & $14.2 \pm 4.1 ; n=5$ & 4.7 & - & +++ & \\
\hline & MOR122-1 & $10.9 \pm 4.6 ; n=17$ & 3.7 & - & ++++ & \\
\hline & MOR160-5 & $8.6 \pm 7.5 ; n=18$ & 2.9 & 2.9 & & + \\
\hline & MOR236-1 & $7.8 \pm 3.3 ; n=12$ & 2.6 & - & ++ & \\
\hline \multirow[t]{3}{*}{ Category III } & MOR244-2 & $3.8 \pm 1.8 ; n=9$ & 1.3 & 1.1 & ++ & \\
\hline & MOR271-1 & $1.3 \pm 2.1 ; n=14$ & 0.4 & 1.0 & +++ & \\
\hline & MOR232-2 & $0.7 \pm 0.8 ; n=10$ & 0.2 & - & +++ & \\
\hline
\end{tabular}

Category IV The following antisense RNA probes stained less than one cell per section, but their existence in the septal organ was confirmed by other means: M0R40-12 and MOR31-12 by genechips (both showed 2.6-fold increment as compared to the MOE) and specific RT-PCR; M0R13-6, M0R257-1, M0R103-15, M0R171-2, M0R279-2, MOR174-13 and MOR225-2 by CDNA cloning.

Category V The following sequences were encountered only in one RNA sample in CDNA cloning, but their existence was not verified by in situ hybridization. M0R3-1; MOR9-2; MOR13-4; MOR14-4; MOR24-2; MOR29-1; MOR30-3; MOR31-4; MOR33-1; MOR33-2; MOR103-16; MOR132-1; MOR135-9; MOR135-13; MOR135-19; MOR135-20; MOR160-1; MOR161-5; MOR163-1; MOR164-1; MOR164-3; MOR171-6; MOR171-22; MOR171-23; MOR171-24; MOR171-43; MOR171-44; MOR172-2; MOR174-10; MOR174-12; MOR174-13; MOR174-15P; MOR174-18; MOR179-3; MOR185-7; MOR185-8; MOR187-1; MOR187-2; MOR188-3; MOR194-1; MOR203-1; MOR204-1; MOR204-23; MOR206-3; MOR206-4; MOR206-6; MOR208-5P; MOR209-1; MOR211-1; MOR224-4; MOR225-6P; MOR225-8P; MOR231-11; MOR232-5; MOR239-5; MOR256-12; MOR257-2; MOR262-5; MOR264-4; MOR274-1; MOR276-1; MOR277-1; MOR281-1; MOR284-1.

The "NBT-BCIP positive cells" were counted and averaged (mean \pm SD) from all the septal organ sections $(n)$ stained by each RNA probe. NBT, Nitroblue tetrazolium; BCIP, 5-bromo-4-chloro-3-indolyl phosphate. The "percentage in OMP-positive cells" for MOR256-3 and MOR244-3 was obtained from double in situ hybridization, and the rest was estimated according to the MOR244-3 data generated in the two ways (see Results). The "fold-change (SO vs MOE) in genechips" was averaged from the two experiments, and a dash indicates "not detected." The number of the plus signs under "cDNA cloning" indicates the number of RNA samples (of four) from which each sequence was encountered.

${ }^{a}$ MORO-2 was previously annotated as a pseudogene MORO-2P in GenBank (accession number AY073944). Our sequencing data indicate this gene has an intact coding region; hence we use MOR0-2 with a new accession number (AY635588).

these four groups equally. Of 312 sequenced clones, we obtained 78 septal olfactory receptor candidates (Table 1). Because of biased amplification of RT-PCR, it is difficult to judge whether such a list is complete or at what levels these genes are expressed.

To identify the most abundant olfactory receptor transcripts, we then used the Affymetrix MOR genechips (Zhang et al., 2004) to evaluate the expression levels of all the mouse olfactory receptor genes in the septal organ. We used the MOE as the comparison baseline with the assumption that the MOE expresses most, if not all, of the olfactory receptor genes (Young et al., 2003; Zhang et al., 2004). Such an approach proved to be effective in identifying highly enriched transcripts in the septal organ (see Discussion). The results from two independent experiments matched very well. There were 7 and 10 genes that had a more than twofold increment relative to the $\operatorname{MOE}(p<0.05)$ in the first and second experiment, respectively, and five of them were in common. Expression of these genes in the septal organ was further confirmed by RT-PCR using specific primers (Table 1 ).

To examine the expression patterns of these candidate genes, we performed in situ hybridization using DIG-labeled antisense RNA probes. Figure $1 B$ shows the staining pattern by the olfactory marker protein (OMP) probe, which labeled all the mature olfactory sensory neurons, indicating the location of the septal organ. We selected 20 candidates for in situ hybridization, including seven genes whose averaged expression levels were more than twofold that of the MOE in the genechips and 13 more genes cloned from at least two (of four) RNA samples (Table 1, Category I-IV). The results demonstrated that the expression patterns of these genes vary considerably in the septal organ (Fig. 1C-I). For the convenience of description, we classified these genes into four categories based on their abundance.

The first category contains only one gene, MOR256-3, whose probe stained too many cells to be counted individually in a 20 $\mu \mathrm{m}$ section (Fig. 1C). We further determined that this gene was expressed in $\sim 50 \%$ of the mature neurons by counting the MOR256-3 cells among the OMP-positive cells in double in situ hybridization with FLU- and DIG-labeled probes (Fig. 2A,C; Table 1).

The second category contains seven genes whose probes reliably labeled more than five cells per section, from the highest MOR244-3 to the lowest MOR236-1 (Fig. 1D-H, Table 1). The percentage for MOR244-3 cells was determined as $12.2 \%$ by double in situ hybridization with the OMP probe (Fig. 2C), and the rest were estimated by normalizing to the MOR244-3 data obtained by single and double in situ hybridization. For example, MOR0-2 probe labeled 23.9 cells per section, and MOR244-3 labeled 35.7 cells on average (Table 1 , Fig. $1 D, E$ ). The percentage for MOR0-2-expressing cells was estimated as (23.9 of 35.7) * $12.2 \%=8.0 \%$. It is worth noting that the expression patterns showed some variations. In the example shown in Figure $1 \mathrm{H}$, MOR160-5 labeled more cells on the right side than on the left side. This difference, however, did not reflect an asymmetric expression of this receptor, because this pattern was only observed in one of five animals.

The third category contains receptor genes whose probes labeled 0.5 to five cells per section (Table 1 ). One example from this category (MOR232-2) is shown in Figure $1 I$. The fourth category contains receptor genes whose probes labeled $<0.5$ cell per section by in situ hybridization, and their existence in the septal organ was confirmed by MOR genechips, specific RT-PCR, or cDNA cloning (Table 1).

It appears that only a small portion (the eight genes in Category I and II) of 84 candidates contribute significantly in the septal organ. We call this gene cohort the major septal olfactory receptor genes, which does not imply that they are specific to the septal organ (see below). To test whether we have generated a relatively complete list of the major genes, we performed in situ hybridization using mixed RNA probes. A mixed probe (Mix5) containing the top five genes in Table 1 labeled $83.7 \pm 3.7 \%(n=$ 13) of the sensory neurons, and another mixed probe (Mix8) containing the top eight genes in Category I and II labeled 93.2 \pm $2.0 \%(n=9)$ (Fig. $2 B, C)$. The additive patterns generated by 
these mixed probes suggested that a single cell expresses only one receptor gene (see below).

In summary, the 11 receptor genes in Category I to III account for $~ 95 \%$ of the cells in the septal organ (Fig. 2D). Therefore, the chance of missing any major genes expressed in $>5 \%$ of the cells is minimal. Consequently, we grouped the rest of the candidate genes that were encountered in only one (of four) septal organ RNA sample by cDNA cloning into Category $\mathrm{V}$, without further verification by in situ hybridization.

\section{Analysis of the septal olfactory receptor genes}

We examined whether the major septal receptor genes form a distinct gene family by mapping them to an unrooted phylogenetic tree containing all the intact mouse olfactory receptors (Fig. 3). The top eight genes all belong to Class II and fall into six subfamilies. Four of them (MOR256-3, MOR244-3, MOR0-2, and MOR122-1) represent unique olfactory receptors, because they do not share high homology with any other member (Table 2). The other four (MOR235-1/MOR236-1 and MOR160-2/MOR160-5) are two pairs of closely related members from two subfamilies. These septal olfactory receptor genes are distributed on multiple chromosomes, including number $17,14,6,15$, and 2 (Table 2). Although these genes only represent a small fraction $(<1 \%)$ of the whole repertoire, they cover a number of major branches among Class II receptors (Fig. 3).

Because several septal receptors are from the same subfamilies, we wished to rule out the possibility that the expression patterns for these genes resulted from cross-hybridization of the RNA probes (supplemental material, available at www. jneurosci.org). Table 2 summarizes the probes we used and their closest matches in the mouse genome and GenBank, other than the desired genes. We selected two close RNA probes (MOR235-1 and MOR236-1) to perform double in situ hybridization, and they detected different sets of cells (Fig. 4A1-A3). Furthermore, a mixed probe of these two produced an additive pattern from each individual (data not shown). Similar results were obtained for another pair of related probes, MOR160-2 and MOR160-5. Therefore all the probes (except two) under our experimental conditions presumably detected mRNAs from a single gene. The two exceptions were MOR244-2 and MOR271-1, each of which has a counterpart (MOR244-1 and MOR270-1) sharing 91 and 98\% nucleotide identity, respectively (Fig. 4B1-B3, Table 2).

Interestingly, every mouse septal olfactory receptor (Table 1 , Category I-III,) has a highly conserved counterpart in the rat (Table 2), which shares at least $91 \%$ nucleotide and $96 \%$ protein identity. By using in situ hybridization, we found that all the major septal receptors identified in the mouse are also expressed in the rat septal organ with similar expression patterns as seen in the mouse (data not shown). This strongly suggests that the septal organ serves a common function across different species.

\section{A single cell expresses only one receptor}

Because we have identified the receptor genes expressed in $\sim 95 \%$ of the septal neurons, it is possible to test the "one receptor-one cell" hypothesis in this area by a thorough examination using double in situ hybridization. We selected these abundant receptor transcripts because they are more likely coexpressed in single neurons. We examined the labeling patterns by the following probe combinations: MOR256-3 versus MOR244-3; MOR256-3 versus a mixture containing MOR244-3, MOR235-1, MOR122-1 and MOR160-2; MOR256-3 versus a mixture containing MOR244-3, MOR0-2, MOR235-1 and MOR122-1; MOR244-3 versus a mixture of the rest six genes in Category II; and MOR256-3 versus a mixture of the 10 genes in Category II and III. One example is shown in Figure 5. In $>7000$ cells examined, we rarely observed coexpression, with only a few cells for which we were not certain. Within the detection sensitivity of in situ hybridization, these data strongly support the hypothesis that a single cell in the septal organ expresses only one receptor gene. 


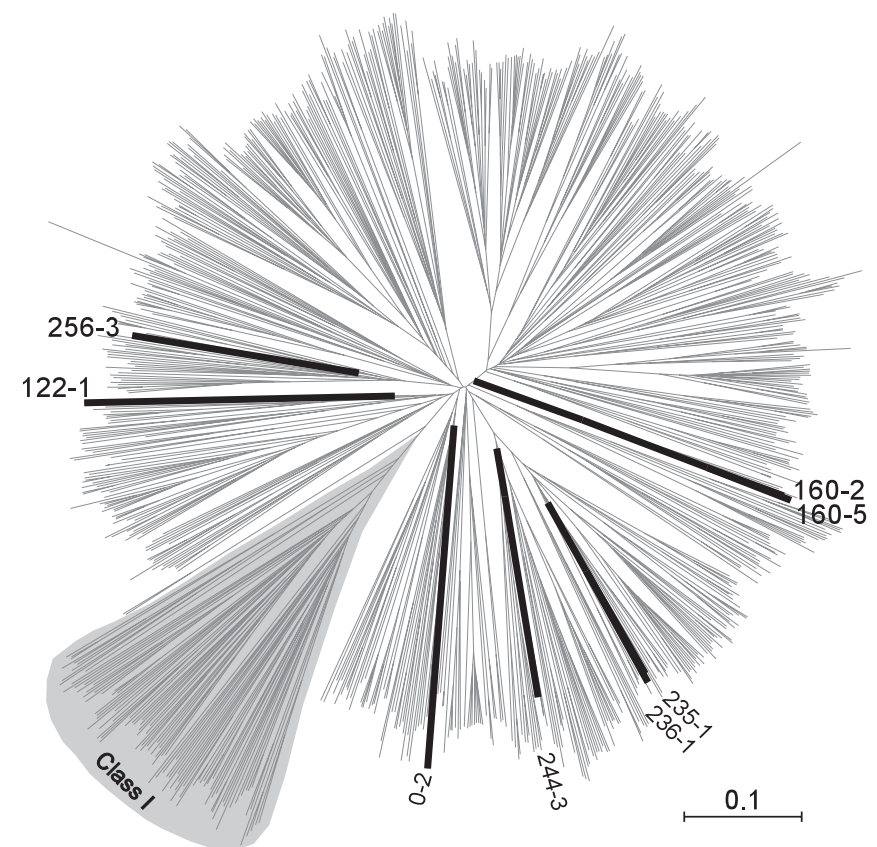

Figure 3. The major septal olfactory receptor genes fall into a few subfamilies in an unrooted phylogenetic tree of the mouse olfactory receptors. The full-length protein sequences of 893 mouse olfactory receptors (Zhang and Firestein, 2002) were aligned using web-based ClustalW, and the resulting multiple alignment was used as input for TreeExplorer to generate the tree. The major septal olfactory receptor genes are in thick and dark lines. The Class I receptors are labeled, and the remaining belong to Class II.

\section{The major septal olfactory receptors are also concentrated in some areas of the MOE}

We investigated whether the major septal receptor genes are also expressed in the MOE and whether their expression patterns vary in accordance with those in the septal organ. Of the 11 genes in Category I to III (Table 1), 10 were detected in the most ventromedial-dorsolateral zone (zone 4) of the MOE (Ressler et al., 1993; Vassar et al., 1993) (Fig. 6A--D). Another gene (MOR0-2) showed an unconventional expression pattern, i.e., it was detected in zone 4 in some cases and in zones $2-3$ in others (data not shown). The results indicate that the septal organ shares its major receptor genes mainly with zone 4 of the MOE.

Among the 10 genes shared by zone 4, their expression patterns in the MOE varied as well, but the profiles did not match those in the septal organ. For instance, the MOR256-3 probe (labeled $50 \%$ of the cells in the septal organ) detected fewer cells than MOR244-3 (labeled 12.2\% in the septal organ) in the MOE (Fig. 6B,C). MOR232-2, which labeled very few cells in the septal organ (Fig. 1I), showed an expression pattern similar to MOR256-3 in the MOE (Fig. 6D).

In addition, these genes were not randomly distributed within zone 4. Instead, most of them (MOR256-3, MOR244-3, MOR232-2, MOR160-2, MOR160-5, MOR122-1, and MOR244-2) labeled more cells in the dorsolateral part, indicated by red lines in Figure $6 E$. We then examined the possibility that these septal receptor genes were also concentrated in these areas in the MOE like in the septal organ. To do that, we mixed eight probes in Category I to III, except the following three: MOR0-2 (not always in zone 4), MOR122-1, and MOR160-5 (labeled very few cells in zone 4 ). These eight probes, which probably detected mRNAs from 10 genes (Table 2), always labeled $\sim 25 \%$ of the cells in the "hot" areas indicated in red by double in situ hybridization with OMP ( $n=15 \mathrm{MOE}$ sections) (Fig. 6E,F). This is much higher than the estimated percentage based on a random scenario (see Discussion). In the same set of experiments, these eight probes labeled $\sim 5 \%$ of the cells in the ventromedial part within zone 4 . These data suggest that the olfactory receptors are not randomly distributed within one zone; instead, some receptors are placed in certain areas with much higher densities.

\section{Discussion}

One goal of the current study was to provide a relatively complete analysis of the chemoreceptors expressed in the septal organ, a distinct chemical sensory organ in the mammalian nose. We achieved this goal by identifying a subset of the olfactory receptor genes expressed in $\sim 95 \%$ (Category I-III) of the mature sensory neurons. The septal organ expresses these genes at varying levels, from the most abundant one in half of the cells to those being present occasionally. We provided strong evidence that one cell expresses only one receptor in the septal organ, a conclusion not yet attained from studies of the MOE. In contrast to the previous view of random distribution of the olfactory receptors within a zone, our results also revealed that some olfactory receptors are present in the septal organ as well as in certain areas of the MOE with unusually high densities to form hot spots.

\section{How many receptor genes does the septal organ express?}

Although we identified $>80$ candidate receptor genes in the septal organ, the expression patterns of these genes varied dramatically, and only a few of them contributes significantly (Table 1). Among these genes, the most abundant one (MOR256-3) was expressed in $\sim 50 \%$ of the cells, and the second one (MOR244-3) in $\sim 12 \%$ of the cells (Figs. 1,2 ). It is possible that we will identify more candidates by cDNA cloning using different degenerate primers, which was our original backup plan in case we had not obtained an expression profile covering $\sim 95 \%$ of the septal organ cells (Category I-III).

The Affymetrix MOR genechips proved to be a powerful tool in identifying highly enriched olfactory receptor transcripts in a tissue. Extra care was taken during the design to achieve the highest specificity and selectivity (Zhang e al., 2004). However, false positives caused by cross-reaction, and false negatives caused by poorly hybridized probe sets, can be only teased out by other methods, such as quantitative RT-PCR and in situ hybridization. Because the MOE expresses most, if not all of the olfactory receptor genes (Young et al., 2003; Zhang et al., 2004), the mRNAs for any given gene would be diluted to a relatively low level. We decided to use the MOE as a baseline for comparison, which proved to be very effective for excluding false positives. The top five genes (MOR256-3, MOR244-3, MOR0-2, MOR235-1, and MOR160-5) that showed the highest fold changes over the MOE were confirmed by in situ hybridization (Table 1, Fig. 1).

It is worth noting that the top three septal olfactory genes in our list were missed by the cDNA cloning approach. This is mainly attributable to the degenerate primers we used. These primers were designed to pick up as many olfactory receptors as possible based on the conserved regions. However, MOR256-3 and MOR0-2 are unusual and do not serve as good templates. Apparently, a few receptor genes (e.g., MOR235-1 and MOR122-1) were favorably amplified by these primers, which further reduced the chance of getting the others. Recently, Kaluza et al. (2004) identified MOR244-3 and plus some other minor ones in the septal organ by using different primers. In summary, by combining cDNA cloning, MOR genechips, and in situ hybridization, we obtained a nearly complete expression profile of the receptor genes in the septal organ. 
Table 2. Analysis of the mouse and rat septal olfactory receptor genes

\begin{tabular}{|c|c|c|c|c|c|c|c|c|}
\hline MOR gene & $\begin{array}{l}\text { Chromosome } \\
\text { location }\end{array}$ & $\begin{array}{l}\text { Accession } \\
\text { number }\end{array}$ & $\begin{array}{l}\text { Probe } \\
\text { length } \\
\text { (bp) }\end{array}$ & $\begin{array}{l}\text { Closest MOR } \\
\text { (homology to } \\
\text { the probe) }\end{array}$ & $\begin{array}{l}\text { Predicted cross- } \\
\text { hybridization }\end{array}$ & $\begin{array}{l}\text { Counterpart in rat } \\
\text { accession number }\end{array}$ & $\begin{array}{l}\text { Chromosome } \\
\text { location }\end{array}$ & $\begin{array}{l}\text { Coding region } \\
\text { homology (\%) }\end{array}$ \\
\hline MOR256-3 & Chr17 & AY073026 & 520 & MOR256-35 (38\%) & None & AY639023 & Chr20 & 94 \\
\hline MOR244-3 & Chr14 & AY073295 & 519 & M0R244-2 (25\%) & None & XM_344332 & Chr15 & 95 \\
\hline MORO-2 & Chr6 & AY635588 & 403 & MOR266-2 (26\%) & None & AY635589 & Chr4 & 95 \\
\hline MOR235-1 & Chr2 & AY073623 & 485 & M0R236-1 (74\%) & None & XM_230271 & Chr3 & 94 \\
\hline M0R160-2 & Chr15 & AY073641 & 497 & M0R160-5 (74\%) & None & AY635590 & Chr7 & 93 \\
\hline MOR122-1 & Chr15 & AY073588 & 512 & MOR204-5 (17\%) & None & XM_235632 & Chr7 & 92 \\
\hline MOR160-5 & Chr15 & AY073813 & 522 & MOR160-2 (34\%) & None & AY635591 & Chr7 & 93 \\
\hline MOR236-1 & Chr2 & AY073890 & 484 & MOR235-1 (76\%) & None & XM_345395 & Chr3 & 92 \\
\hline MOR244-2 & Chr14 & AY073294 & 484 & M0R244-1 (91\%) & MOR244-1 & XM_223999 & Chr15 & 93 \\
\hline MOR271-1 & Chr16 & AY073019 & 496 & MOR270-1 (98\%) & MOR270-1 & AY635592 & Chr11 & 91 \\
\hline MOR232-2 & Chr2 & AY073107 & 481 & M0R231-2 (22\%) & None & XM_230268 & Chr3 & 94 \\
\hline
\end{tabular}

The "Closest MOR" members were determined by BLAT (mouse genome) and BLAST (GenBank) search using the probe sequences (supplemental material, available at www.jneurosci.org).
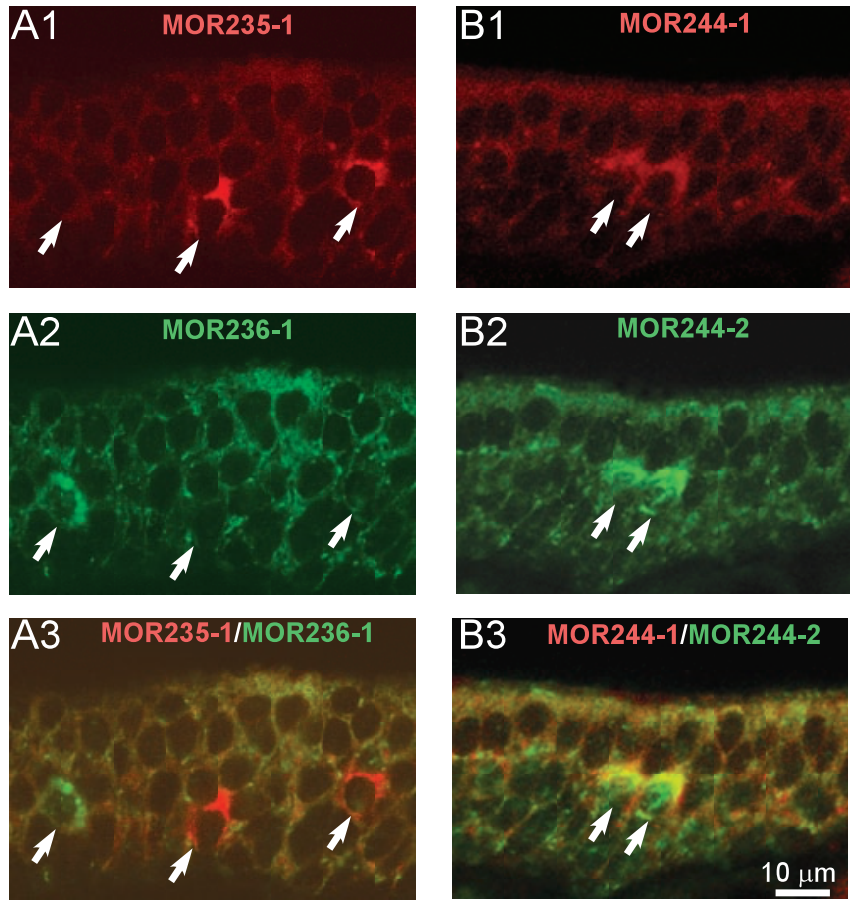

Figure 4. Potential cross-hybridization between related olfactory receptor probes. $A 1-A 3$, The section was hybridized by DIG-labeled MOR235-1 (red, A1) and FLU-labeled M0R236-1 (green, $A 2$ ) probes. The two probes share 74\% identity, and there was no cross-hybridization (A3). B1-B3, The section was hybridized by DIG-labeled M0R244-1 (red, B1) and FLU-labeled MOR244-2 (green, B2) probes. The two probes share 91\% identity, and there was crosshybridization (B3). Arrows mark stained cells.

Identification of a few major receptor genes plus many minor ones is consistent with the projection pattern from the septal organ to the main olfactory bulb (Giannetti et al., 1992; Levai and Strotmann, 2003; Ma et al., 2003). The septal organ projects mainly to the posterior, ventromedial olfactory bulb and targets onto a few densely labeled glomeruli and many lightly labeled ones. The densely labeled ones presumably receive inputs mainly or solely from the septal organ (so-called "septal" glomeruli), whereas the lightly labeled ones receive inputs from both the septal organ and the MOE. It is a reasonable assumption that the few major receptor genes identified in the current study correspond with the few septal glomeruli. The sensory neurons expressing MOR256-3 (Cutforth et al., 2003), MOR244-3, MOR244-2, MOR235-1, and MOR236-1 (Tsuboi et al., 1999) have been shown to project to the glomeruli in the ventromedial
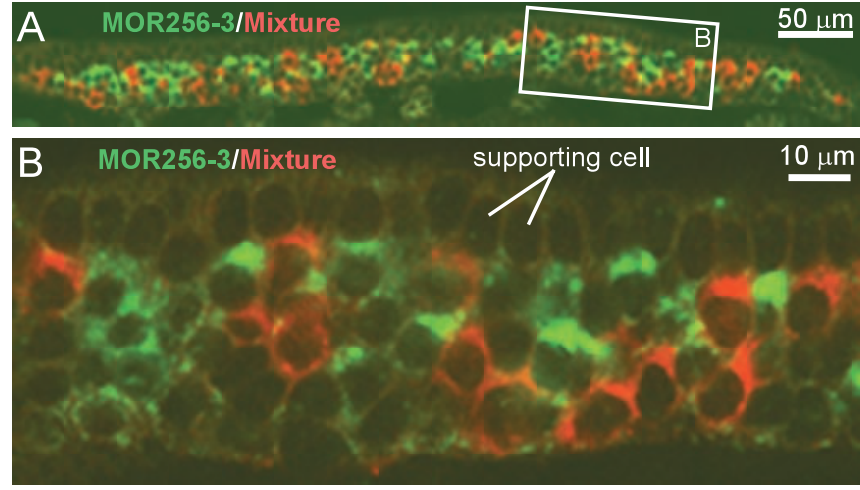

Figure 5. A single neuron expresses only one receptor gene in the septal organ. The section was hybridized by FLU-labeled MOR256-3 (green) and DIG-labeled (red) probes containing MOR244-3, MORO-2, MOR235-1, and MOR122-1. The entire septal organ section ( $A$ ), and part of it at higher magnification $(B)$ are shown.

region, and also to their lateral counterparts. It would be interesting to see whether the sensory neurons expressing a single receptor (e.g., MOR256-3) in the septal organ and in the MOE project separately to the medial and the lateral glomerulus, respectively.

\section{Does one cell express only one receptor?}

The one receptor-one cell rule serves as a working hypothesis for the MOE and provides a basis for models of olfactory information coding and processing. However, direct evidence from the MOE has been lacking because of the vast number of receptor genes expressed in any area (Rawson et al., 2000; Mombaerts, 2004). Because the septal organ mainly expresses a few receptor genes, we were able to provide two pieces of evidence based on the receptor genes covering $\sim 95 \%$ of the cells. First, mixed receptor gene probes always generated additive expression patterns from individual ones. Second, we almost never observed coexpression in various combinations of all the major receptor genes in double in situ hybridization. These results strongly support the hypothesis that a single cell expresses only one receptor.

Recent evidence indicates that the one receptor-one cell rule is likely ensured by negative feedback through the receptor gene product (Serizawa et al., 2003; Lewcock and Reed, 2004). Because one of the studies focuses on the MOR244 family, of which several members are present in the septal organ, it is plausible that the general one receptor-one cell rule that applies to both the MOE and the septal organ is achieved by similar mechanisms. 

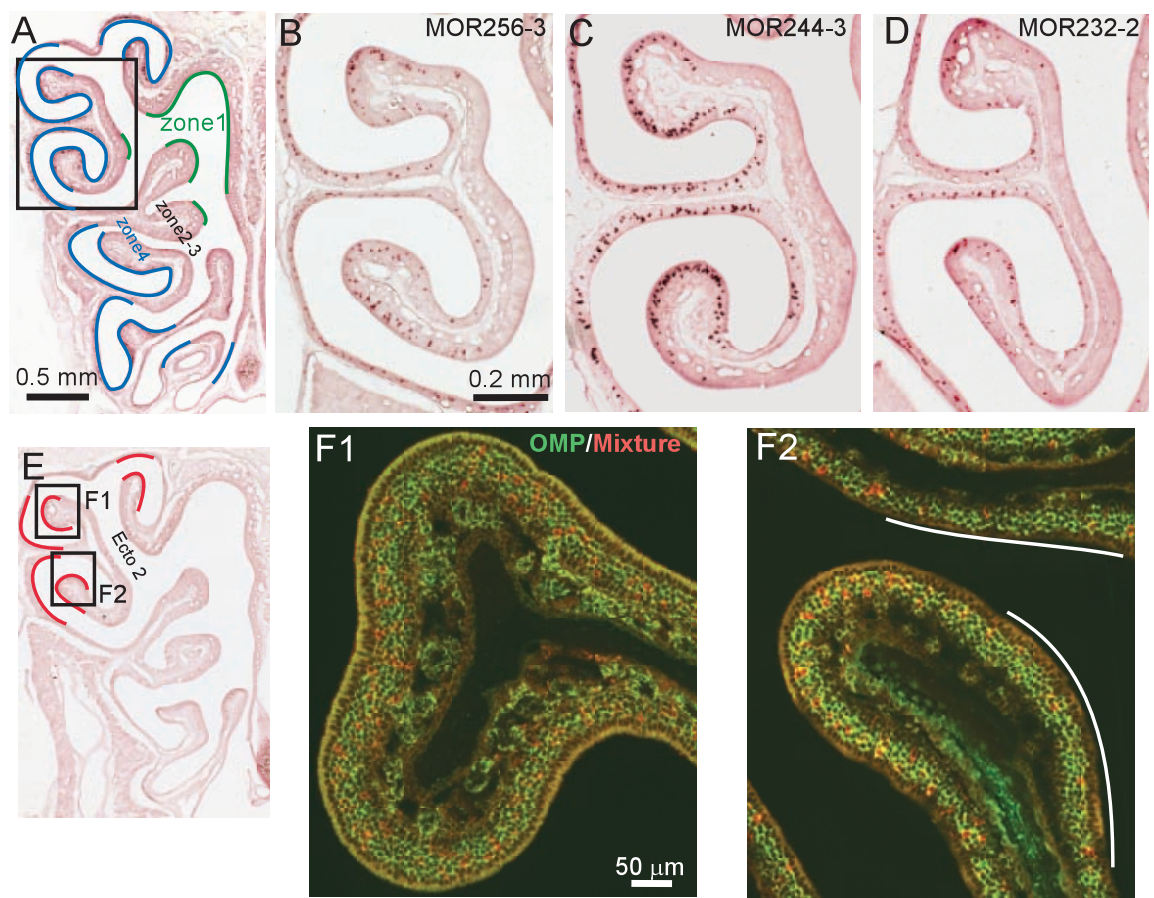

Figure 6. The major septal receptor genes are also expressed in the MOE and concentrated in certain areas. $A$, Different zones (zone 1 in green and zone 4 in blue) are approximately indicated in an MOE hemisection. Pictures $B-D$ were taken approximately from the area within the rectangle. $B-D$, The mid-anteroposterial MOE sections were hybridized with the following antisense RNA probes: M0R256-3 (B), MOR244-3 (C), and MOR232-2 (D). E, Most of the major septal olfactory receptor genes are also concentrated in the areas indicated by red lines within zone 4. Ecto 2, Ectoturbinate 2. F1, F2, The MOE sections were hybridized by FLU-labeled OMP (green) and DIG-labeled (red) probes containing MOR256-2, MOR244-3, MOR235-1, M0R160-2, M0R236-1, MOR244-2, MOR271-1, and MOR232-2. Two images $(F 1, F 2)$ were taken in the areas indicated in $E$. The white lines in $F 2$ indicate relatively "cold areas", where fewer cells were labeled.

\section{How special is the septal organ?}

We previously demonstrated that the sensory neurons in the septal organ and in the MOE share the major signal transduction pathway and show similar odorant responses (Ma et al., 2003). The special properties and function of the septal organ may result from its unique position in the nasal cavity and the receptors it expresses. Although the major septal receptor genes are also shared by the MOE (Fig. 6), their expression patterns do not match those in the septal organ (Fig. 1). Some receptors, especially the MOR256-3, are present in the septal organ with unusually high densities.

This raises two possibilities for the function of the septal organ. First, the septal organ is particularly sensitive to certain ligands and serves a special function related to these ligands. Second, although the septal organ mainly covers a small fraction $(<1 \%)$ of the whole receptor repertoire, previous EOG recordings (Marshall and Maruniak, 1986) and our unpublished results indicate that the septal organ neurons can respond to many odorants with distinct chemical structures. This leads to the hypothesis that these receptors are very broadly tuned. In other words, the olfactory receptors vary dramatically in their response spectra and may play different roles in odor detection and discrimination. By concentrating a few broadly tuned olfactory receptors in the air path, the septal organ may serve as a general odor detector in the nose. We will distinguish the two possibilities by systematically searching for the ligands of the septal organ neurons.

\section{Are there hot spots in the nose?}

The distribution of individual olfactory receptor genes within a zone is generally characterized as random based on in situ hybrid- ization data (Ressler et al., 1993; Vassar et al., 1993). However, physiological recordings have revealed hot spots in the olfactory epithelium responding to certain odors (Mackay-Sim and Kesteven, 1994; Youngentob et al., 1995). Here we showed that most of the major septal receptor genes are not randomly distributed within a zone. Instead, these genes appear concentrated in the dorsolateral rather than the ventromedial portion of epithelial zone 4 . The eight probes used in Figure $6 F$, which likely detected 10 genes, labeled $\sim 25 \%$ of the cells in certain areas. This is $\sim 10$ times higher than the estimated percentage based on a random scenario. Assume that there are 1200 olfactory receptor genes (Young et al., 2002, 2003; Zhang and Firestein, 2002), and each of the following zones expresses one third of the receptors (zone 1 , zones $2-3$, and zone 4 ) with zones $2-3$ treated as a single zone (Iwema et al., 2004). Then 10 genes in zone 4 will only account for $2.5 \%$ of the cells on average. Our results indicate that at least some olfactory receptors are concentrated in certain areas in the nose, which may underlie the hot spots seen in physiological recordings.

The observation of the hot spots in the nose has important implication on the development and regeneration of the olfactory epithelium. The precursor cells, which give rise to the new receptor neurons, may not have a broad and random selection of the olfactory receptors within a zone; instead, their selection may be restricted within a small subset of the receptors. As a result, the receptor neurons have their fate predetermined at very early stages and can be differentially regulated based on which receptor they express.

\section{References}

Adams DR, McFarland LZ (1971) Septal olfactory organ in Peromyscus. Comp Biochem Physiol A 40:971-974.

Buck L, Axel R (1991) A novel multigene family may encode odorant receptors: a molecular basis for odor recognition. Cell 65:175-187.

Cutforth T, Moring L, Mendelsohn M, Nemes A, Shah NM, Kim MM, Frisen J, Axel R (2003) Axonal ephrin-As and odorant receptors: coordinate determination of the olfactory sensory map. Cell 114:311-322.

Dulac C, Torello AT (2003) Molecular detection of pheromone signals in mammals: from genes to behaviour. Nat Rev Neurosci 4:551-562.

Giannetti N, Saucier D, Astic L (1992) Organization of the septal organ projection to the main olfactory bulb in adult and newborn rats. J Comp Neurol 323:288-298.

Iwema CL, Fang H, Kurtz DB, Youngentob SL, Schwob JE (2004) Odorant receptor expression patterns are restored in lesion-recovered rat olfactory epithelium. J Neurosci 24:356-369.

Kaluza JF, Gussing F, Bohm S, Breer H, Strotmann J (2004) Olfactory receptors in the mouse septal organ. J Neurosci Res 76:442-452.

Kimbell JS, Godo MN, Gross EA, Joyner DR, Richardson RB, Morgan KT (1997) Computer simulation of inspiratory airflow in all regions of the F344 rat nasal passages. Toxicol Appl Pharmacol 145:388-398.

Kratzing JE (1984) The structure and distribution of nasal glands in four marsupial species. J Anat 139:553-564.

Levai O, Strotmann J (2003) Projection pattern of nerve fibers from the septal organ: DiI-tracing studies with transgenic OMP mice. Histochem Cell Biol 120:483-492.

Lewcock JW, Reed RR (2004) A feedback mechanism regulates monoallelic odorant receptor expression. Proc Natl Acad Sci USA 101:1069-1074. 
Ma M, Grosmaitre X, Iwema CL, Baker H, Greer CA, Shepherd GM (2003) Olfactory signal transduction in the mouse septal organ. J Neurosci 23:317-324.

Mackay-Sim A, Kesteven S (1994) Topographic patterns of responsiveness to odorants in the rat olfactory epithelium. J Neurophysiol 71:150-160.

Marshall DA, Maruniak JA (1986) Masera's organ responds to odorants. Brain Res 366:329-332.

Mombaerts P (2004) Odorant receptor gene choice in olfactory sensory neurons: the one receptor-one neuron hypothesis revisited. Curr Opin Neurobiol 14:31-36.

Rawson NE, Eberwine J, Dotson R, Jackson J, Ulrich P, Restrepo D (2000) Expression of mRNAs encoding for two different olfactory receptors in a subset of olfactory receptor neurons. J Neurochem 75:185-195.

Ressler KJ, Sullivan SL, Buck LB (1993) A zonal organization of odorant receptor gene expression in the olfactory epithelium. Cell 73:597-609.

Rodolfo-Masera T (1943) Su 1'esistenza di un particolare organo olfacttivo nel setto nasale della cavia e di altri roditori. Arch Ital Anat Embryol 48:157-212.

Serizawa S, Miyamichi K, Nakatani H, Suzuki M, Saito M, Yoshihara Y, Sakano H (2003) Negative feedback regulation ensures the one receptor-one olfactory neuron rule in mouse. Science 302:2088-2094.

Tsuboi A, Yoshihara S, Yamazaki N, Kasai H, Asai-Tsuboi H, Komatsu M,
Serizawa S, Ishii T, Matsuda Y, Nagawa F, Sakano H (1999) Olfactory neurons expressing closely linked and homologous odorant receptor genes tend to project their axons to neighboring glomeruli on the olfactory bulb. J Neurosci 19:8409-8418.

Vassar R, Ngai J, Axel R (1993) Spatial segregation of odorant receptor expression in the mammalian olfactory epithelium. Cell 74:309-318.

Young JM, Friedman C, Williams EM, Ross JA, Tonnes-Priddy L, Trask BJ (2002) Different evolutionary processes shaped the mouse and human olfactory receptor gene families. Hum Mol Genet 11:535-546.

Young JM, Shykind BM, Lane RP, Tonnes-Priddy L, Ross JA, Walker M, Williams EM, Trask BJ (2003) Odorant receptor expressed sequence tags demonstrate olfactory expression of over 400 genes, extensive alternate splicing and unequal expression levels. Genome Biol 4:R71.

Youngentob SL, Kent PF, Sheehe PR, Schwob JE, Tzoumaka E (1995) Mucosal inherent activity patterns in the rat: evidence from voltage-sensitive dyes. J Neurophysiol 73:387-398.

Zhang X, Firestein S (2002) The olfactory receptor gene superfamily of the mouse. Nat Neurosci 5:124-133.

Zhang X, Rogers M, Tian H, Zhang X, Zou D, Liu J, Ma M, Shepherd GM, Firestein S (2004) High throughput microarray detection of odorant receptor gene expression in the mouse. Proc Natl Acad Sci USA, in press. 